\title{
HEART-LUNG VERSUS DOUBLE-LUNG TRANSPLANTATION FOR SUPPURATIVE LUNG DISEASE
}

Clifford W. Barlow, MD

Robert C. Robbins, MD

Marc R. Moon, MD

Olufemi Akindipe, MD

James Theodore, MD

Bruce A. Reitz, MD
Objective: The purpose of this study was to compare outcomes after heart-lung or double-lung transplantation in patients undergoing transplantation because of end-stage suppurative lung disease. Methods: We reviewed our experience in patients with cystic fibrosis or bronchiectasis who had heart-lung or double-lung transplantation between January 1988 and September 1997. Twenty-three patients (14 male, 21 cystic fibrosis) had heart-lung transplantation and 24 patients (8 male, 19 cystic fibrosis) had double-lung transplantation. There were no statistically significant differences between the groups in age, weight, preoperative creatinine level, cytomegalovirus status, maintenance immunosuppression, or donor demographics. Patients received induction therapy with monoclonal (OKT3) or polyclonal (rabbit anti-thymocyte globulin) antibody. Results: Sixteen of 24 patients had double-lung transplantation after 1994 whereas 13 of 22 patients had heart-lung transplantation before 1991, allowing longer follow-up for the heart-lung group. Mean waiting times for transplantation were $270 \pm 245$ days (heart-lung) and $361 \pm 229$ days (double-lung; $P=.20$ ). The 1-, 3-, and 5-year actuarial survival figures were respectively $86 \%, 82 \%$, and $65 \%$ (heart-lung) and 96\%, 75\%, and unavailable (double-lung; $P=$ no significant difference). The 1-, 3-, and 5-year rates of freedom from obliterative bronchiolitis were respectively $77 \%, 61 \%$, and $45 \%$ (heart-lung) and $86 \%, 78 \%$, and unavailable (double-lung; $P=$ no significant difference). Linearized overall infection rates (events/100 patient-days) were $2.05 \pm 0.33$ (heart-lung) and $2.34 \pm 0.34$ (double-lung; $P=$ NS) at 3 months. Thirty-day survival was $100 \%$ (heart-lung) and $96 \%$ (doublelung). There were 7 late deaths among heart-lung recipients (3 obliterative bronchiolitis, 2 infection, 0 graft coronary artery disease, 2 other) whereas 2 late deaths related to obliterative bronchiolitis occurred in double-lung recipients. Graft coronary artery disease (all stenoses < $50 \%$ ) affected $15 \%$ of heart-lung survivors, whereas 3 double-lung recipients $(12.5 \%)$ required either bronchial dilatation or stenting. Conclusion: Heart-lung and double-lung transplantation provide similar palliation for patients with end-stage suppurative lung disease. Therefore double-lung transplantation should be the preferred operation for most patients with end-stage suppurative lung disease. (J Thorac Cardiovasc Surg 2000;119:466-76)
From Falk Cardiovascular Research Center, Stanford University School of Medicine, Stanford, Calif.

Read at the Seventy-eighth Annual Meeting of The American Association for Thoracic Surgery, Boston, Mass, May 3-6, 1998.

Received for publication May 8, 1998; revisions requested Sept 8, 1998; revisions received April 15, 1999; accepted for publication Oct 22, 1999

Address for reprints: Robert C. Robbins, MD, Falk Cardiovascular Research Center, Stanford University School of Medicine, Stanford, CA 94305-5407 (E-mail: robbins@ @leland.stanford.edu). Copyright @ 2000 by Mosby, Inc.

0022-5223/2000 $\$ 12.00+0 \quad \mathbf{1 2 / 6 / 1 0 4 0 4 0}$

doi: $10.1067 / \mathrm{mtc} .2000 .104040$ ung transplantation has become an established option in the therapy of end-stage lung disease. ${ }^{1}$ The major disease subgroups for which lung transplantation is considered are emphysema, suppurative lung disease, pulmonary hypertension, and pulmonary fibrosis. ${ }^{2}$ Overall survival is improving, but figures remain inferior to the results achieved with transplantation of other organs. ${ }^{3}$ However, even for patients in whom lung transplantation may not provide a survival benefit, quality of life and pulmonary function indices are improved. ${ }^{1}$

Suppurative lung diseases pose several problems to 
the transplant team. Transplantation options are limited, with single-lung transplantation having no practical role because bilateral sepsis mandates excision of both lungs. ${ }^{2}$ In addition, patients frequently have extensive pleural adhesions that prolong the operative time, are associated with an increased risk of bleeding, and potentially increase the postoperative recovery time. Finally, patients with cystic fibrosis (CF) make up the largest single group of patients referred for transplantation with end-stage suppurative lung disease. These patients have nutritional deficiencies that are compounded by malabsorption syndrome, colonization of sinuses and airways with resistant organisms, and systemic comorbidities including hepatic and pancreatic dysfunction. Despite these issues, several centers have reported survival and pulmonary function benefits after both heart-lung ${ }^{4-6}$ and sequential double-lung ${ }^{7-9}$ transplantation in patients with suppurative lung disease. The purpose of this review is to compare outcomes after heart-lung and double-lung transplantation in patients with suppurative lung disease at Stanford University Medical Center.

\section{Methods}

The study consisted of a retrospective review and analysis of the cases of patients who had undergone either heart-lung or double-lung transplantation because of end-stage suppurative lung disease at Stanford. All patients with CF or bronchiectasis who underwent transplantation between January 1988 and September 1997 were included. Patient information for this study was obtained from the Stanford Transplant Database and a thorough review of clinical records.

Patient selection. Patients with end-stage suppurative lung disease who were accepted for transplantation generally had a forced expiratory volume in 1 second $\left(\mathrm{FEV}_{1}\right)$ less than $30 \%$ of predicted, a $\mathrm{PO}_{2}$ less than $60 \mathrm{~mm} \mathrm{Hg}$, and a $\mathrm{PCO}_{2}$ greater than $45 \mathrm{~mm} \mathrm{Hg}$ while breathing room air. Selection criteria were similar to those published elsewhere. ${ }^{10}$ Acutely ill patients, including those requiring mechanical ventilation, were not considered good candidates and no patient who was receiving ventilator support underwent transplantation during the period of this study. ${ }^{11}$ Potential recipients were motivated and had a suitable social support network. Transplantation was not offered to patients with significant multisystem diseases or those with a recent history of malignancy. Patients with CF with extrapulmonary sites of infection, those with pan-resistant Pseudomonas, Burkholderia cepacia, or Aspergillus, were temporarily taken off of the active list until the infection was cleared. Patients with CF underwent sinus flushing via maxillary antrostomies before being listed. The same criteria were applied in selecting patients for both heartlung and double-lung procedures.

Psychological support and exercise rehabilitation of the patients were maximized once the patient was accepted for transplantation. Nutritional supplementation was optimized, with percutaneous gastrostomy if necessary, and regular prophylactic sinus flushing was continued to decrease the bacterial load in the upper respiratory tract in the patients with CF.

Operative techniques. Patients received heart-lung transplantation, in combination with "domino-donor" cardiac transplantation when possible, ${ }^{4,12}$ or sequential double-lung transplantation. Domino-donor hearts were treated the same as any donor heart and were placed in the normal distribution algorithm for allocation based on the waiting time of candidates on the United Network for Organ Sharing (UNOS) cardiac transplant list. Ten recipients of heart-lung allografts donated their native heart for cardiac transplantation. There were various reasons for not using the other 13 native hearts for cardiac transplantation: no suitable recipient was identified because of size and/or blood type $(n=9)$, poor left ventricular function $(\mathrm{n}=3)$, and transplantation occurred before implementation of the domino procedure $(n=1)$.

Patients were not prospectively matched with donors according to cytomegalovirus status. In heart-lung recipients we ensured that the donor weight was within $25 \%$ of the recipient weight. Heart-lung transplantation was initially the preferred procedure for patients with suppurative lung disease on the basis of our experience with this operation for patients with pulmonary hypertension and congenital heart disease. ${ }^{13}$ The trend gradually evolved to favor sequential double-lung transplantation as other centers reported their experiences with that procedure..$^{7-9}$

The technique of organ procurement has been described previously. ${ }^{14}$ Alprostadil (prostaglandin $\mathrm{E}_{1}$ ) was infused 15 minutes before procurement. Pulmonoplegic solution, consisting of modified Euro-Collins solution with $8 \mathrm{mEq} / \mathrm{L}$ $\mathrm{MgSO}_{4}$ and $65 \mathrm{~mL} / \mathrm{L}$ of $50 \%$ dextrose, was infused into the pulmonary artery just before aortic crossclamping. If the recipient was to receive a double-lung transplant, the pulmonary artery was divided at its bifurcation and the trachea was divided at the carina. The lungs were separated just before implantation during the recipient operation. In 10 heart-lung cases the heart was preserved for domino-donor operation. Dissection of the superior vena cava was extended cranially in both the donor and heart-lung recipient. Direct bicaval anastomoses were performed in the domino transplantation procedure, and this technique has been adapted to all heart-lung procedures.

Heart-lung transplantation was done via a median sternotomy early in the series and via a transverse thoracostomy ("clamshell") incision later. ${ }^{15}$ Great care was taken to preserve phrenic nerve pedicles and to avoid damage to the vagus nerves. The posterior pericardium was left intact and bronchial collateral vessels were diligently controlled to avoid hemorrhage from the posterior mediastinum. During excision of the septic lungs, shed blood was discarded to avoid bacterial contamination. The tracheal anastomosis was sutured end to end with running 3-0 polypropylene sutures. We did not "telescope" or wrap the anastomosis with omentum.

Double-lung transplantation was done through a clamshell incision to maximize exposure of the pleural spaces. We did 
not perform the classic en bloc procedure, but preferred the sequential double-lung technique. ${ }^{16}$ The right lung was transplanted first while ventilation was maintained to the left lung. Cardiopulmonary bypass (CPB) was occasionally necessary during implantation of the first lung. The bronchial anastomosis was sutured end to end with running 4-0 polypropylene sutures, also without telescoping or omental wrapping. We initially attempted to avoid CPB during insertion of both lungs, although we now believe that this is not necessary. In most cases, once the right lung was transplanted, CPB was instituted during implantation of the left lung. This strategy facilitated exposure of the left hilum and gradual reperfusion of the right lung at low pressure in an attempt to minimize reperfusion injury.

In patients with $\mathrm{CF}$, regardless of whether they had heartlung or double-lung transplantation, either tranexamic acid or aprotinin was used in an attempt to reduce postoperative hemorrhage. The argon beam coagulator was frequently used to control hemorrhage from the pleural surface.

Postoperative care. Monitoring and nursing routines were similar for all patients. Patients received active diuresis and fluid infusions were minimized in the early postoperative period, which frequently necessitated the use of vasopressor support. Patients were extubated when oxygenation was acceptable, hemodynamics were stable, and bleeding had minimized and when they were awake. Patients with CF were treated perioperatively with anti-Pseudomonas antibiotics as guided by the most recent sputum and sinus cultures. Prophylactic ganciclovir and cytomegalovirus immune globulin (CytoGam) were given when either the donor or recipient was cytomegalovirus seropositive. ${ }^{17}$

Triple-drug maintenance immunosuppression was used during the study period. Cyclosporine (INN: ciclosporin) administration was begun 12 to 24 hours after transplantation once hemodynamics and urine output were stable. The target level was 150 to $200 \mathrm{ng} / \mathrm{dL}$ by postoperative day 7 . Azathioprine was given at $2 \mathrm{mg} / \mathrm{kg}$ per day after initial loading with $4 \mathrm{mg} / \mathrm{kg}$ in the operating room. Maintenance dosages were guided by the white blood cell count. Methylprednisone was given at a dose of $500 \mathrm{mg}$ in the operating room after protamine administration and then $125 \mathrm{mg}$ every 8 hours for the first 24 hours. Steroids were then withheld for 2 weeks to allow bronchial healing, after which oral prednisone administration was started at a dosage of 0.6 $\mathrm{mg} / \mathrm{kg}$ in 2 divided doses. Steroids were weaned over a period of 3 to 4 weeks to a maintenance dosage of $0.2 \mathrm{mg} / \mathrm{kg}$ per day. Perioperative induction therapy was routinely used during the study period. Patients received either OKT3 (5 $\mathrm{mg} /$ day) or rabbit anti-thymocyte globulin (RATG; $2.5 \mathrm{mg} / \mathrm{kg}$ per day), on the basis of the availability of locally produced RATG. We observed fewer episodes of rejection and improved survival in patients treated with RATG and, as a consequence, the majority of patients in this study received RATG. ${ }^{18}$ Once patients were ambulatory and tolerating a normal diet, they were discharged from the hospital.

Follow-up. Patients were followed up by the HeartLung/Lung Transplant Service. They were seen twice a week for the first 3 weeks and then weekly for another 4 weeks. Consultations were then spaced according to progress. Patients remained at the Stanford Home-tel to receive ambulatory treatment for the first 3 months, after which consultations were spaced according to progress. Long-term followup consultations were undertaken at least once a year, but usually about once every 6 months. Surveillance bronchoscopic examination was undertaken at 2, 4, 8, and 12 weeks and then at 6 months and 1 year. Pulmonary function tests, a chest radiograph, and arterial blood gas evaluations were done at each clinic visit. Patients with $\mathrm{CF}$ were followed up by the otolaryngology service and received frequent sinus flushes.

Statistical analysis. Numeric results are expressed as mean \pm SD. Differences in age, height, weight, and operative times (continuous variables) were analyzed by the 2 -tailed $t$ test. Differences in sex, proportion of patients with $\mathrm{CF}$, and cytomegalovirus status (discrete variables) were compared by continuity-adjusted $\chi^{2}$ test. Actuarial life-table data were calculated by the Cutler-Ederer method. Time-related event-free rates are reported from actuarial estimates as the mean \pm SE. Comparison between actuarial curves was made by the Gehan method. The linearized rate of events was calculated as the number of events occurring per 100 patient-days. We acknowledge the severe limitations of this very small retrospective study.

\section{Results}

Between January 1988 and September 1997, 47 patients underwent transplantation because of suppurative lung disease. Twenty-three patients had heart-lung transplants and 24 patients had double-lung transplants. Pretransplantation patient demographics are shown in Table I. The groups were generally comparable in terms of age, sex, preoperative diagnosis, height, weight, creatinine level, bilirubin level, cytomegalovirus status, and donor characteristics. All patients received induction therapy. Fourteen of 23 in the heartlung group received RATG, as did 21 of 24 in the double-lung transplantation group. All the other patients received OKT3. The annual numbers and types of procedures are listed in Table II. Thirteen of 23 patients had heart-lung transplantation before 1991, whereas 16 of 24 patients had double-lung transplantation after 1994. The domino-donor operation was begun in 1989 and 10 of the hearts of heart-lung recipients were donated for cardiac transplantation.

Perioperative data for the two groups are shown in Table III. Mean waiting time for heart-lung transplantation was $270 \pm 245$ days and for double-lung transplantation was $361 \pm 229$ days $(P=.20$, not significant). Fifteen of 24 patients receiving double-lung transplantation had CPB for insertion of the second lung, 1 patient required CPB support for insertion of 
Table I. Demographics of heart-lung recipients, double-lung recipients, and donors

\begin{tabular}{|c|c|c|c|c|c|}
\hline Variable & $\begin{array}{c}\text { Heart-lung } \\
\text { recipients }\end{array}$ & $\begin{array}{c}\text { Heart-lung } \\
\text { donors }\end{array}$ & $\begin{array}{c}\text { Double-lung } \\
\text { recipients }\end{array}$ & $\begin{array}{c}\text { Double-lung } \\
\text { donors }\end{array}$ & $\begin{array}{c}\text { Comparison } \\
\text { (recipients) }\end{array}$ \\
\hline Patient No. & 23 & 23 & 24 & 24 & \\
\hline Age (y) & $29 \pm 8.9$ & $27 \pm 13.7$ & $30 \pm 10.1$ & $28 \pm 13.8$ & $P=.88(\mathrm{NS})$ \\
\hline Weight $(\mathrm{kg})$ & $49 \pm 13.3$ & $58 \pm 16.9$ & $49 \pm 9.0$ & $59 \pm 12.9$ & $P=.95(\mathrm{NS})$ \\
\hline Height $(\mathrm{cm})$ & $163 \pm 17.3$ & $167 \pm 16.7$ & $157 \pm 23.2$ & $162 \pm 10.4$ & $P=.36(\mathrm{NS})$ \\
\hline $\operatorname{Sex}(M / F)$ & $14 / 9$ & $15 / 8$ & $8 / 16$ & $11 / 13$ & NS \\
\hline Sex mismatch (yes/no) & $5 / 18$ & & $9 / 15$ & & NS \\
\hline Domino donor (yes/no) & $10 / 13$ & & NA & & \\
\hline $\mathrm{CF} /$ bronchiectasis & $21 / 2$ & & $19 / 5$ & & NS \\
\hline CMV (positive/negative) & $8 / 15$ & & $12 / 12$ & & NS \\
\hline CMV mismatch (yes/no) & $8 / 15$ & & $7 / 17$ & & NS \\
\hline
\end{tabular}

Data are means \pm SD. Differences in age, weight, and height analyzed by 2-tailed $t$ test; differences in sex, diagnosis, and cytomegalovirus (CMV) status analyzed by the Pearson $\chi^{2}$ test. $C F$, Cystic fibrosis; $N S$, not significant; $N A$, not applicable.

Table II. Transplants undertaken for suppurative lung disease

\begin{tabular}{lcc}
\hline Year & $\begin{array}{c}\text { Heart-lung } \\
\text { transplants }\end{array}$ & $\begin{array}{c}\text { Double-lung } \\
\text { transplants }\end{array}$ \\
\hline 1988 & 3 & 0 \\
1989 & 4 & 0 \\
1990 & 6 & 1 \\
1991 & 2 & 1 \\
1992 & 1 & 1 \\
1993 & 0 & 2 \\
1994 & 3 & 3 \\
1995 & 2 & 3 \\
1996 & 1 & 4 \\
1997 & 1 & 9 \\
Total & 23 & 24 \\
\hline
\end{tabular}

both lungs, and 8 patients had double-lung transplantation done without the use of CPB. There were no statistically significant differences in outcomes between patients who required CPB and patients who had the operation without CPB. Ischemic times for insertion of the heart-lung block were not significantly shorter than ischemic times for insertion of the first lung $(P=.09)$, but they were significantly shorter than times for the second lung $(P<.001$, Table III). One patient in the heart-lung group and 2 in the double-lung group underwent re-exploration to control bleeding. Data were not available for total blood use, but decreased blood loss has been noted in all patients undergoing lung transplantation, especially those with $\mathrm{CF}$, since the introduction of antifibrinolytic agents. The duration of ventilation and intensive care unit days required by each group were similar. Total length of hospital stay tended to be longer in heart-lung recipients, although this did not reach statistical significance. No patient underwent retransplantation because of early graft failure. Thirty-
Table III. Perioperative data

\begin{tabular}{lccl}
\hline Variable & $\begin{array}{c}\text { Heart-lung } \\
\text { recipients }\end{array}$ & $\begin{array}{c}\text { Double-lung } \\
\text { recipients }\end{array}$ & Comparison \\
\hline Waiting time (d) & $270 \pm 245$ & $361 \pm 229$ & $P=.20$ (NS) \\
$\begin{array}{l}\text { Ischemic time (min) } \\
\text { Heart-lung }\end{array}$ & $190 \pm 92$ & & \\
First lung & & $232 \pm 70$ & $P=.09^{*}$ (NS) \\
$\quad$ Second lung & & $331 \pm 87$ & $P<.001^{*}$ \\
CPB (yes/no) & $23 / 0$ & $15 / 9$ & \\
CPB time (min) & $168 \pm 37$ & $166 \pm 68$ & $P=.94$ (NS) \\
Reoperation for bleeding & 1 & 2 & \\
Duration of ventilation (d) & & & \\
$\quad$ Mean & $6.4 \pm 10.9$ & $9.4 \pm 29.7$ & $P=.65$ (NS) \\
Median & 1 & 1 & \\
$\quad$ Range & $1-38$ & $1-144$ & \\
Hospital stay (d) & & & \\
$\quad$ Mean & $38 \pm 34$ & $26 \pm 25$ & $P=.18$ (NS) \\
Median & 27 & 18 & \\
Range & $13-161$ & $2-133$ & \\
\hline
\end{tabular}

Data are means \pm SD. Differences are analyzed by 2 -tailed $t$ test. $N S$, Not significant.

*Versus heart-lung.

day survival for the heart-lung transplant group was $100 \%$. There was 1 early death in the group undergoing double-lung transplantation. This patient was a 46year-old man with $\mathrm{CF}$. He had recently required ventilator support for a period of 10 days and was severely physically and nutritionally weakened. He had extensive adhesions and therefore had a prolonged insertion time for both lungs (276 and 359 minutes). Both lungs were transplanted during CPB because of inadequate ventilation. After the operation the patient had extensive blood loss necessitating transfusion and re-exploration because of bleeding. Acute respiratory distress syndrome subsequently developed, and the patient required extracorporeal membrane oxygenation. He 


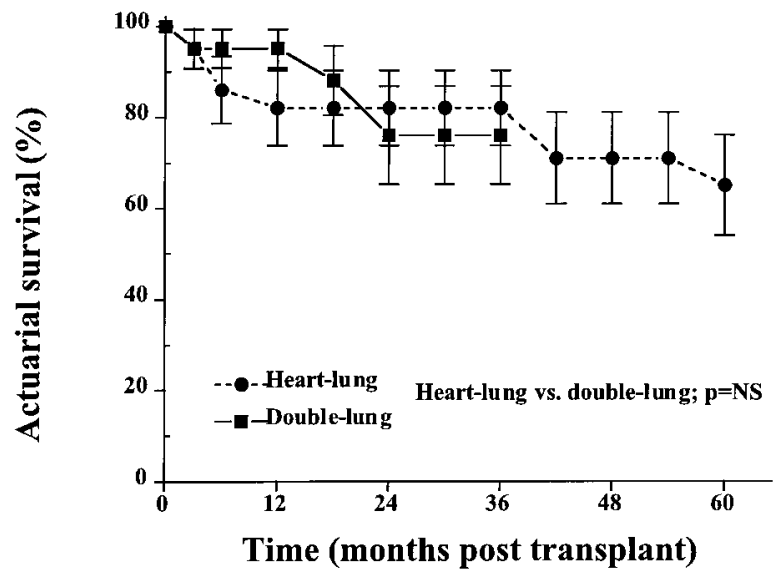

Fig 1. Comparison of actuarial survival between heart-lung and double-lung recipients. Time-related event-free rates are mean \pm SE. There was no difference between the curves by Gehan testing.

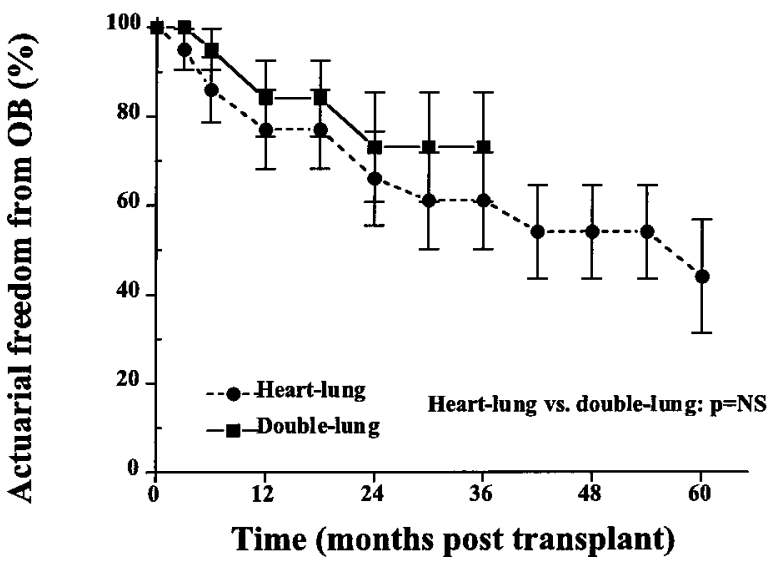

Fig 2. Comparison of actuarial freedom from biopsy-proven OB between heart-lung and double-lung recipients. Timerelated event-free rates are mean $\pm \mathrm{SE}$. There was no difference between the curves by Gehan testing.

Table IV. Linearized infection rates (events/100 patient-days)

\begin{tabular}{|c|c|c|c|c|c|c|c|c|c|}
\hline \multirow[b]{3}{*}{ Type of infection } & \multicolumn{8}{|c|}{ Time period (mo) } & \multirow[b]{3}{*}{ Comparison } \\
\hline & \multicolumn{2}{|c|}{$0-3$} & \multicolumn{2}{|c|}{$3-6$} & \multicolumn{2}{|c|}{$6-12$} & \multicolumn{2}{|c|}{$12-24$} & \\
\hline & $H-L$ & $D-L$ & $H-L$ & $D-L$ & $H-L$ & $D-L$ & $H-L$ & $D-L$ & \\
\hline Bacterial & $1.03(0.23)$ & $1.55(0.28)$ & $0.11(0.08)$ & $0.45(0.15)$ & $0.14(0.09)$ & $0.20(0.11)$ & $0.17(0.10)$ & $0.22(0.14)$ & NS \\
\hline Viral (CMV) & $0.61(0.18)$ & $0.50(0.16)$ & $0.17(0.10)$ & $0.50(0.16)$ & $0.06(0.06)$ & $0.10(0.08)$ & $0.06(0.11)$ & $0.11(0.07)$ & NS \\
\hline Fungal & $0.34(0.13)$ & $0.29(0.12)$ & $0.11(0.07)$ & $0(0)$ & $0(0)$ & $0.02(0.02)$ & $0.02(0.02)$ & $0.06(0.05)$ & NS \\
\hline Overall & $2.05(0.33)$ & $2.34(0.34)$ & $0.44(0.16)$ & $0.95(0.22)$ & $0.21(0.11)$ & $0.33(0.14)$ & $0.26(0.12)$ & $0.38(0.17)$ & NS \\
\hline
\end{tabular}

Data are means (SD). $H-L$, Heart-lung transplant; $D-L$, double-lung transplant; $N S$, not significant; $C M V$, cytomegalovirus.

continued to bleed, his condition became hemodynamically unstable, and sepsis developed. Despite maximal inotropic and pressor support, the patient died on the second postoperative day.

Actuarial survival was similar for the two groups (Fig 1). Longer follow-up data were available for heart-lung recipients because of more frequent use of this procedure early in the series. Survivorship at 1,3 , and 5 years, respectively, was $86 \%, 82 \%$, and $65 \%$ for heartlung recipients and $96 \%, 75 \%$, and unavailable for double-lung recipients. There was no statistically significant difference between survival figures by Gehan analysis. Actuarial survivorship for patients who received induction therapy with RATG at 1,3 , and 5 years, respectively, was $84 \%, 75 \%$, and $56 \%$ for heartlung recipients $(\mathrm{n}=13)$ and $95 \%, 84 \%$, and unavailable for double-lung recipients $(\mathrm{n}=21)$. There was no statistically significant difference in survival between the transplantation procedure groups when subjects who received OKT3 induction therapy were excluded.
Linearized rates of bacterial, fungal, protozoal, viral, and overall infections for the two groups are shown in Table IV. There was no significant difference for any type of infection at any period. There were 2 deaths as a result of infection after heart-lung transplantation that occurred after 3 and 4 months, respectively. Both patients had complicated postoperative courses, were never discharged from the hospital, and had multiorgan failure before dying of sepsis. There were no longterm infection-related deaths in double-lung recipients.

Actuarial rates of freedom from biopsy-proven obliterative bronchiolitis (OB) are shown in Fig 2. There was no significant difference between the two groups. Actuarial rates of freedom from lung rejection at 3 months and at 1,3 , and 5 years, respectively, in heartlung recipients were $43 \%, 37 \%, 21 \%$, and $21 \%$ and in double-lung recipients were $61 \%, 56 \%, 48 \%$, and unavailable $(P=.10$, Fig 3$)$. Actuarial rates of freedom from heart rejection at 3 months and 1, 3, and 5 years, 
Table V. Complications

\begin{tabular}{|c|c|c|}
\hline Complication & $\begin{array}{l}\text { Heart-lung } \\
\text { transplants }\end{array}$ & $\begin{array}{c}\text { Double-lung } \\
\text { transplants }\end{array}$ \\
\hline \multicolumn{3}{|l|}{ Surgical } \\
\hline \multicolumn{3}{|l|}{ Airway } \\
\hline Stricture & 0 & 3 \\
\hline Stent & & 1 \\
\hline Balloon & & 2 \\
\hline Dehiscence & 0 & 0 \\
\hline \multicolumn{3}{|l|}{ Gastrointestinal } \\
\hline Gastric atony (>1 wk) & 1 & 1 \\
\hline Cholelithiasis & 0 & 1 \\
\hline Bleeding & 0 & 1 \\
\hline \multicolumn{3}{|l|}{ Pulmonary } \\
\hline Resection & 0 & 1 \\
\hline \multicolumn{3}{|l|}{ Miscellaneous } \\
\hline Axillary vein thrombosis & 0 & 1 \\
\hline SVC anastomotic stricture & 1 & NA \\
\hline Graft failure (re-listed) & 0 & 1 \\
\hline \multicolumn{3}{|l|}{ Medical } \\
\hline \multicolumn{3}{|l|}{ Cardiac } \\
\hline Graft coronary disease $(<50 \%)$ & 3 & NA \\
\hline Graft mitral valve prolapse & 1 & NA \\
\hline \multicolumn{3}{|l|}{ Renal } \\
\hline Temporary dialysis & 1 & 2 \\
\hline Nephrotic syndrome & 2 & 0 \\
\hline \multicolumn{3}{|l|}{ Central nervous system } \\
\hline Cerebrovascular accident & 0 & 1 \\
\hline Seizure & 1 & 2 \\
\hline \multicolumn{3}{|l|}{ Metabolic } \\
\hline New insulin-dependent diabetes & 1 & 1 \\
\hline
\end{tabular}

$S V C$, Superior vena cava; $N A$, not applicable.

respectively, in heart-lung recipients were $80 \%, 75 \%$, $69 \%$, and $61 \%$ (Fig 4). Actuarial rates of freedom from angiographically significant graft coronary artery disease (all stenoses were $<50 \%$ ) at 1,3 , and 5 years were $100 \%, 85 \%$, and $85 \%$, respectively. No patient died of cardiac complications or received cardiac retransplantation in the heart-lung cohort. However, in one heartlung recipient superior vena caval obstruction developed, which was treated with radiologically guided stent placement. A second patient, an 8-year heart-lung transplant survivor, has mitral regurgitation from myxomatous degeneration of the donor mitral valve. He is currently being considered for mitral valve replacement.

A list of surgical and medical complications is shown in Table V. Three patients in the double-lung group had significant bronchial stenoses. Two of these instances resolved with balloon dilatation. A third patient, who also had a course severely complicated by $B$ cepacia pneumonia, required 3 stents to the left lung and 3 to the right lung. This patient remains in New York Heart Association class IV and is currently relisted for heart-

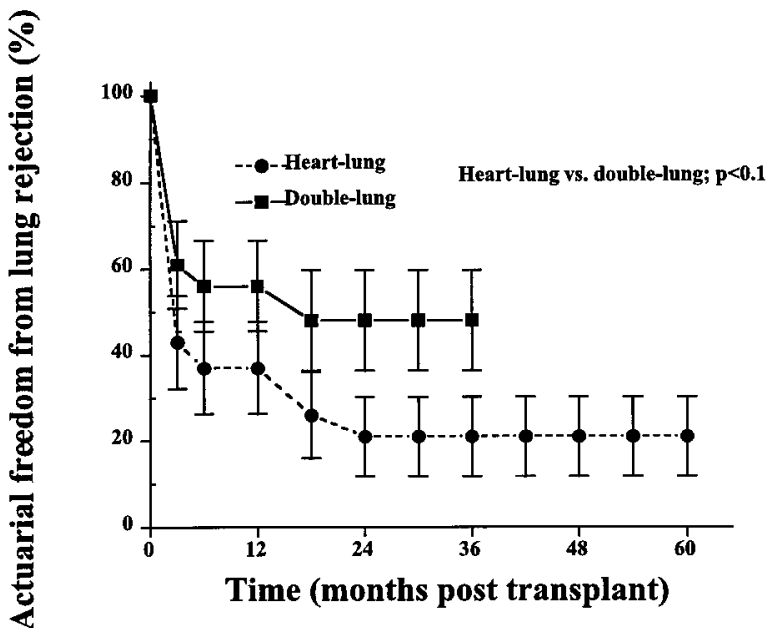

Fig 3. Comparison of actuarial freedom from lung rejection between heart-lung and double-lung recipients. Time-related event-free rates are mean \pm SE. The difference between the curves did not reach statistical significance by Gehan testing $(P=.10)$.

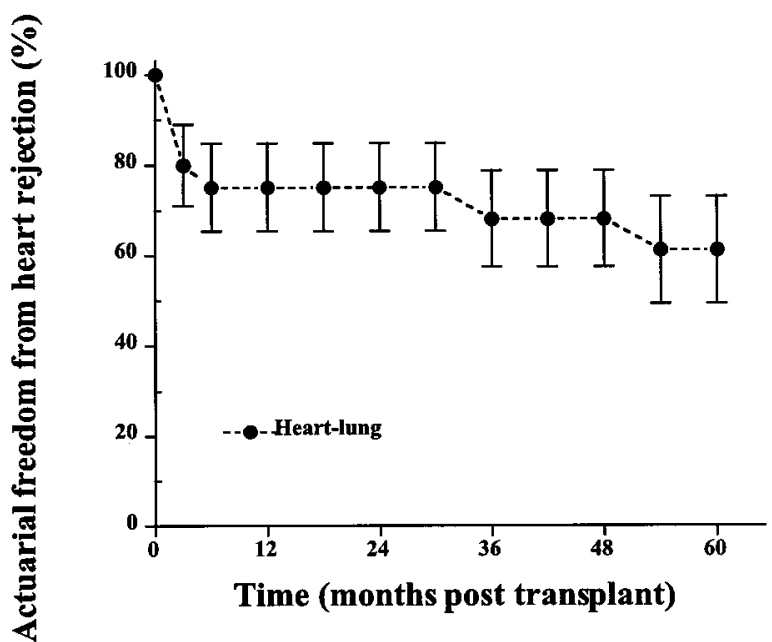

Fig 4. Actuarial freedom from heart rejection for heart-lung recipients. Time-related event-free rates are mean \pm SE.

lung transplantation. A degree of gastric atony was encountered in most patients in both groups because of the proximity of the surgical dissection to the vagus nerves. This was managed with cisapride or metaclopramide and only 1 patient in each group had severe symptoms persisting longer than 1 week. One doublelung recipient had a significant gastrointestinal tract bleeding episode. This resolved with transfusion and medical management. One double-lung recipient with CF had cholecystitis necessitating cholecystectomy 5 

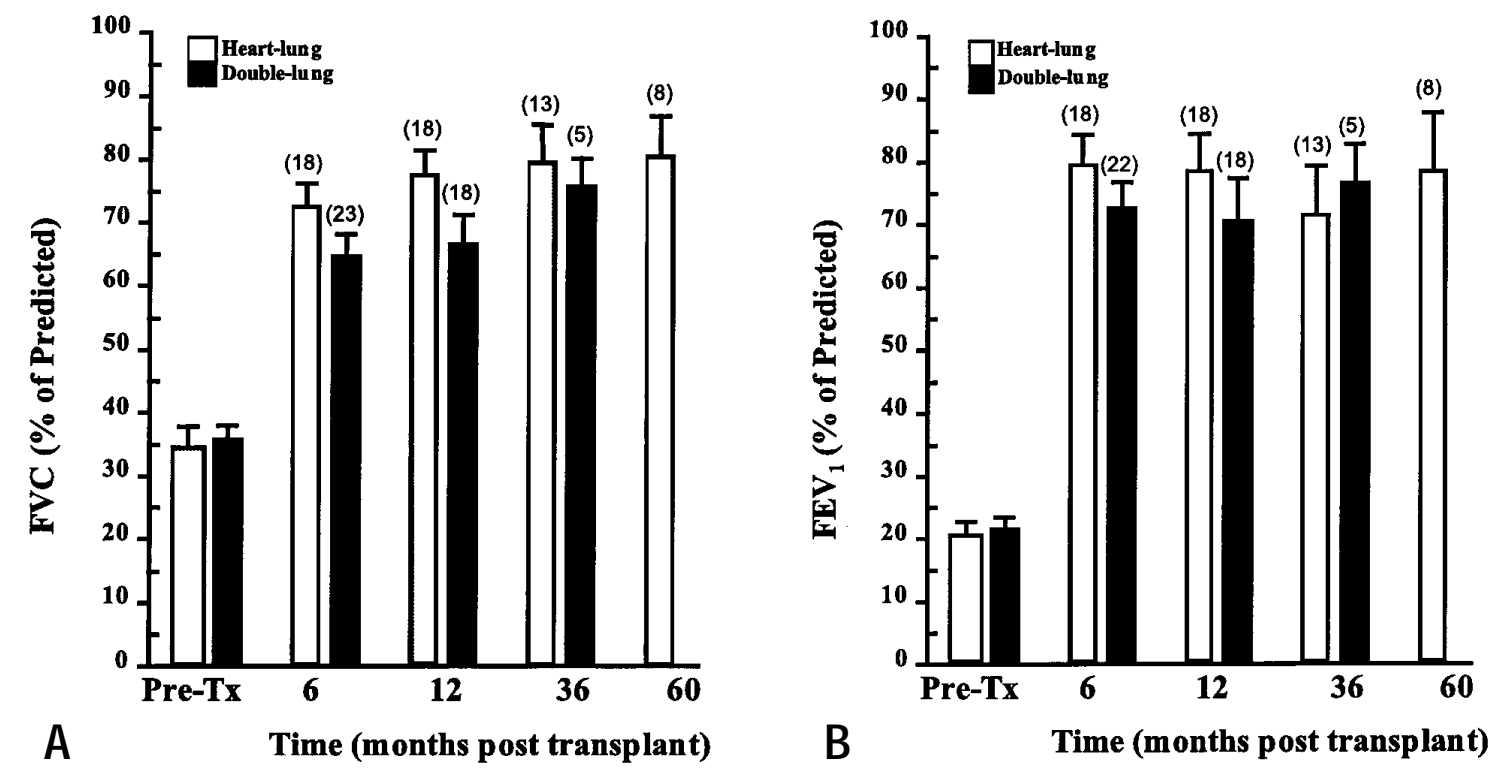

Fig 5. Early and sustained improvement in pulmonary function test results after heart-lung and double-lung transplantation $(T x)$ : A, forced vital capacity $(F V C) ; \mathbf{B}, \mathrm{FEV}_{1}$. Columns show mean with SE. The $\mathrm{n}$ value is shown in parentheses.

months after transplantation. In 1 patient in the doublelung group an axillary vein thrombosis developed. One patient in the heart-lung group had the development of renal failure necessitating temporary dialysis, as did 2 in the double-lung group. One patient in the heart-lung group and 2 in the double-lung group had temporary seizure disorders.

There were 7 late deaths in the heart-lung transplant group, 2 of which were a result of infectious complications as previously described. A third patient died 38 days after transplantation of complications after a cerebrovascular accident. A fourth patient died after 3 years of liver failure, which was complicated by severe OB. The remaining 3 deaths were caused by OB-related complications after 1,3, and 4 years, respectively. There were 2 late deaths in the double-lung recipients, both of which occurred after almost 2 years and were related to $\mathrm{OB}$.

Patient pulmonary function test results are shown in Fig. 5, $A$, for forced vital capacity and Fig. 5, $B$, for $\mathrm{FEV}_{1}$. These demonstrate an immediate and sustained improvement in forced vital capacity and $\mathrm{FEV}_{1}$ after both heart-lung and double-lung transplantation.

\section{Discussion}

Survival and long-term pulmonary function benefits were achieved in patients with suppurative lung disease after both heart-lung and double-lung transplantation with no apparent survival advantage being observed for either procedure. Each procedure has both theoretical and practical advantages. Our strategy in the late 1980s and early 1990s was to perform heart-lung transplantation in patients with suppurative lung disease because of our early experience and familiarity with this procedure. ${ }^{13}$ We gradually evolved our approach as other centers reported good results with double-lung transplantation. ${ }^{7-9}$ On the basis of the present analysis, double-lung transplantation is the preferred operation for patients with end-stage suppurative lung diseases.

Although the first lung transplantation was done by Hardy in 1963, it was not until the initial experience with heart-lung transplantation at Stanford that a reasonable degree of success was achieved with pulmonary replacement. ${ }^{2,13}$ Shortly afterward, improved results of single-lung transplantation were reported in subjects with pulmonary fibrosis. ${ }^{19}$ Because bilateral sepsis mandates the excision of both lungs in suppurative lung disease, the first procedure done in these patients was heart-lung transplantation. The first double-lung transplantations for $\mathrm{CF}$ were done by the en bloc technique. There were initial concerns that tracheal anastomotic healing would be poorer than after heart-lung transplantation, because of the loss of mediastinal collaterals. The technique of double-lung transplantation evolved to a bibronchial anastomosis with the use of CPB support. ${ }^{20}$ Later, the clamshell incision 
was introduced, which allowed improved exposure and introduction of the sequential insertion technique, with or without $\mathrm{CPB} .{ }^{21}$ Some centers attempt to avoid $\mathrm{CPB}$ to minimize blood loss and the subsequent need for blood transfusion and possible reperfusion injury. ${ }^{8}$ Others prefer to use CPB during insertion of the second lung to reduce operative time, improve exposure, and avoid overperfusing the newly implanted first lung. ${ }^{7}$

Fears that patients with $\mathrm{CF}$ would do worse than other patients after transplantation have not been realized. Indeed, an analysis of recent data from the Joint United Network for Organ Sharing (UNOS) and the International Society of Heart and Lung Transplantation (ISHLT) indicated that among all patients referred for lung transplantation, the clearest survival benefit is in patients with $\mathrm{CF}^{1}{ }^{1}$ This is largely because survival of patients with $\mathrm{CF}$ awaiting transplantation is significantly worse than that of patients with other diseases such as emphysema. As a result, the requirement for organs for lung transplantation in suppurative lung disease is greater than the current limited supply.

The successful introduction of sequential doublelung transplantation for $\mathrm{CF}$ led several investigators to question whether heart-lung transplantation should remain an option for these patients. ${ }^{2,7,8}$ There are several theoretical advantages of double-lung transplantation. The incidence of accelerated graft coronary artery disease after heart-lung transplantation may be as high as $12 \%, 22$ and this is avoided in double-lung transplantation, as is the concern of placing a denervated heart in a patient without cor pulmonale. Improved anastomotic techniques have reduced the incidence of airway anastomotic dehiscence and strictures in double-lung transplantation. ${ }^{7,8,20,21}$ There may be less mediastinal bleeding in double-lung transplantation, especially if CPB can be avoided, whereas reoperation rates because of bleeding as high as $28 \%$ have been reported in heartlung transplantation. ${ }^{23}$ The vagus nerves may be at less risk in double-lung transplantation. ${ }^{7}$ Finally, initial reports of outcome after heart-lung transplantation in patients with $\mathrm{CF}$ in the United States were disappointing, with 1-year survival of only $42 \% .^{24}$

Conversely, some transplantation centers continue to maintain that heart-lung transplantation retains certain advantages for patients with end-stage suppurative lung diseases..$^{5}$ Early reports of heart-lung transplantation in patients with $\mathrm{CF}$ in the United Kingdom showed a promising 1-year survival of about $75 \%$. $^{4,5}$ There is only one airway anastomosis and this has a lower risk of dehiscence because it retains its blood supply through coronary-to-bronchial collateral vessels. ${ }^{6}$ The tracheal airway is larger, which reduces the risk of stricture encountered after bronchial anastomoses, ${ }^{6}$ and more "infected" airway is removed. The occasionally high incidence of airway complications, reported by some centers in double-lung transplantation, 9,25 is therefore avoided. The operation is simpler and therefore faster with shorter ischemic times than those reported in some series of double-lung transplantation. Although anecdotal reports have found that a prolonged ischemic time does not necessarily correlate with poor postoperative pulmonary function, ${ }^{8}$ basic principles motivate the transplantation surgeon to keep organ ischemic time as short as possible. The potential use of domino-donor hearts means that organs should not be wasted. The domino-donor heart has the potential advantages of a conditioned right ventricle, of being fully analyzed before transplantation, and of not being from a brain-dead donor. Finally, the current UNOS policy is to give priority to patients on the heartlung waiting lists, which may result in shorter waiting times for these recipients. In the present study we sought to assess whether the theoretical advantages of the 2 procedures translated into actual survival or clinical benefits for patients with end-stage suppurative lung disease.

Organs were offered by our organ procurement organization for individual patients in order of longest waiting time. According to guidelines agreed to by UNOS, priority was given to heart-lung candidates before double-lung candidates. Length of waiting time was shorter for heart-lung recipients in this study, although this figure did not reach statistical significance. Waiting times tend to be longer now than they were several years ago when most of the heart-lung patients in this study received their transplants, but waiting-list priority still favors this group.

We found no difference in the incidence of re-exploration because of bleeding between the two groups in this study. Data on blood transfusion requirements were not available. Postoperative emphasis on minimizing transfusions and using pressors when necessary has helped reduce length of ventilation and intensive care unit stay in recent years. There was no significant difference between the groups in duration of ventilation and hospital stay. The tendency, although not significant, for double-lung recipients to have shorter hospital stays might reflect the emphasis on early discharge in recent years when most double-lung transplantation procedures were done.

The major end point of our study was patient survival. There was no difference between the two groups, both early and at longer-term follow-up. The survivorship is actually higher than that for patients undergoing 
these two procedures at Stanford for other diagnostic indications. Overall rates of lung rejection and $\mathrm{OB}$ were also similar in the two groups. Accelerated graft coronary artery disease, which affects $15 \%$ of heartlung survivors in this study, has not resulted in death or retransplantation. We suspect that $\mathrm{OB}$ affects patients more aggressively than graft coronary artery disease and is the major chronic rejection equivalent after heart-lung transplantation. ${ }^{26}$ This incidence of $\mathrm{OB}$ is similar to that described in other studies of doublelung $^{8}$ and heart-lung ${ }^{6}$ transplantation. The double-lung group had a higher incidence of airway complications, although our results compared well with those of some reported series. ${ }^{9,25}$ It is possible that earlier administration of steroids, which we avoid until 2 weeks after transplantation to assist bronchial healing, could actually help reduce airway complications by decreasing the immunologic effects of ischemia and early rejection. ${ }^{5}$ The patient groups had similar lung function improvements at both early and longer-term follow-up.

Rates of cytomegalovirus infection were similar for both groups. Our policy of ganciclovir and cytomegalovirus immune globulin (CytoGam) prophylaxis has been instituted since 1990 and affected almost all the patients in both groups in this study. ${ }^{17}$ Aerosolized amphotericin B prophylaxis was instituted at Stanford in 1993 and would have affected almost all double-lung transplant recipients and a minority in the heart-lung transplant group. ${ }^{27}$ Despite this, there was no significant difference in the rate of fungal infection between the two groups.

In keeping with procedures at most centers in the United States, candidates referred for transplantation because of end-stage suppurative lung disease at Stanford during the past few years have been listed for double-lung transplantation. However, the present analysis suggests that neither double-lung nor heartlung transplantation has any advantage from a survival or pulmonary function perspective. Indeed, both procedures have certain advantages and drawbacks. We continue to list most of our patients for double-lung transplantation alone. Patients with $\mathrm{CF}$ who require simultaneous liver transplantation are listed for heartlung transplantation because of the shorter operative time required to perform the thoracic procedure. We double-list patients at the extremes of height and weight, as well as more critically ill patients, so that they obtain maximum benefit on the UNOS waiting list.

New medical treatments and refinements in gene therapy might, in the future, improve survival and quality of life in patients with $\mathrm{CF}^{28,29}$ At present, however, because both heart-lung and double-lung transplantation provide similar palliation for patients with endstage suppurative lung disease, double-lung transplantation is the preferred operation for this group of patients primarily because the recipient retains his or her own normally functioning heart.

We thank Tom McCloskey for help with preparing the manuscript. We also thank Pat Gamberg and Joan Miller for assistance with data acquisition.

\section{REFERENCES}

1. Hosenpud JD, Bennett LE, Berkley MK, Edwards EB, Novick RJ. Effect of diagnosis on survival benefit of lung transplantation for end-stage lung disease. Lancet 1998;351:24-7.

2. Patterson GA. Indications: unilateral, bilateral, heart-lung, and lobar transplant procedures. Clin Chest Med 1997;18:225-30.

3. Hosenpud JD, Bennett LE, Keck BM, Fiol B, Novick RJ. The registry of the International Society for Heart and Lung Transplantation: fourteenth official report-1997. J Heart Lung Transplant 1997;16:691-712.

4. Yacoub MH, Banner NR, Khaghani A, et al. Heart-lung transplantation for cystic fibrosis and subsequent domino heart transplantation. J Heart Transplant 1990;9:459-67.

5. de Leval MR, Smyth R, Whitehead B, et al. Heart and lung transplantation for terminal cystic fibrosis: a 4-year experience. J Thorac Cardiovasc Surg 1991;101:633-42.

6. Higgenbottam T, Otulana BA, Wallwork J. Transplantation of the lung. Eur Respir J 1990;3:594-605.

7. Hasan A, Corris PA, Healy M, et al. Bilateral sequential lung transplantation for end stage septic lung disease. Thorax 1995;50:565-6.

8. Egan TM, Frank CD, Mill MM, et al. Improved results of lung transplantation for patients with cystic fibrosis. J Thorac Cardiovasc Surg 1995;109:224-35.

9. Shennib H, Noirclerc M, Ernst P, et al. Double-lung transplantation for cystic fibrosis. Ann Thorac Surg 1992;54:27-32.

10. Marshall SE, Kramer MR, Lewiston NJ, et al. Selection and evaluation of recipients for heart-lung and lung transplantation. Chest 1990;98:1488-94.

11. Hutter JA, Despins P, Higenbottam T, Stewart S, Wallwork JA. Heart-lung transplantation: better use of resources. Am J Med 1988;85:4-11.

12. Cochrane AD, Smith JA, Esmore DS. The "domino-donor" operation in heart and lung transplantation. Med J Aust 1991;155: 589-93.

13. Reitz BA, Wallwork JL, Hunt SA, et al. Heart-lung transplantation: successful therapy for patients with pulmonary vascular disease. N Engl J Med 1982;306:557-64.

14. Shumway SJ, Burdive J, Boiman RM. Combined harvest of heart and lungs: technique and results. Transplant Proc 1991;23:1236-8.

15. Reitz BA, Pennock JL, Shumway NE. Simplified operative method for heart and lung transplantation. J Surg Res 1981;31:1-5.

16. Egan TM, Detterbeck FC. Technique and results of double lung transplantation. Chest Surg Clin North Am 1993;3:89-111.

17. Soghikian MV, Valentine VG, Berry GJ, Patel HR, Robbins RC, Theodore J. Impact of ganciclovir prophylaxis on heart-lung and lung transplant recipients. J Heart Lung Transplant 1996;15:881-7.

18. Robbins RC, Valentine VG, Theodore J, Reitz BA. Improved sur- 
vival with RATG versus OKT3 induction therapy following heartlung and lung transplantation. Circulation 1996;94(Suppl):I479.

19. Toronto Lung Transplant Group. Unilateral lung transplantation for pulmonary fibrosis. N Engl J Med 1986;314:1140-5.

20. Noirclerc M, Chazalette JP, Metras D, et al. Les transplantations bipulmonaries: rapport de la premiere observation Francaise et commentaires des cinq suivantes. Ann Chir 1989;43:597-600.

21. Pasque MK, Cooper JD, Kaiser LR, Haydock DA, Triantaffillou A, Trulock EP. Improved technique for bilateral lung transplantation: rationale and initial clinical experience. Ann Thorac Surg 1990;49:785-91.

22. Dawkins KD, Jamieson SW, Hunt SA, et al. Long-term results, hemodynamics and complications after combined heart and lung transplantation. Circulation 1985;71:919-26.

23. Sharples LD, Scott JP, Dennis C, et al. Risk factors for survival following combined heart-lung transplantation. Transplantation 1994;57:218-23.

24. Frist WH, Fox MD, Campbell PW, Fiel SB, Loyd JE, Merrill WH. Cystic fibrosis treated with heart-lung transplantation: North American results. Transplant Proc 1991;23:1205-6.

25. Ramirez JC, Patterson GA, Winton TL, de Hoyos AL, Miller JD, Maurer JR. Bilateral lung transplantation for cystic fibrosis. J Thorac Cardiovasc Surg 1992;103:287-94.

26. Joshi A, Oyer PE, Berry GJ, Billingham ME. Heart-lung transplantation: cardiac clinicopathological correlations. Cardiovasc Pathol 1996;5:153-8.

27. Reichenspurner H, Gamberg P, Nitschke M, et al. Significant reduction in the number of fungal infections after lung-, heartlung, and heart transplantation using aerosolized amphotericin B prophylaxis. Transplant Proc 1997;29:627-8.

28. Ramsey BW, Astley SJ, Aitken ML, et al. Efficacy and safety of short-term administration of aerosolized recombinant human deoxyribonuclease in patients with cystic fibrosis. Am Rev Respir Dis 1993;148:145-51.

29. Zabner J, Couture LA, Gregory RJ, Graham SM, Smith AE, Welsh MJ. Adeno-virus mediated gene transfer transiently corrects the chloride transport defect in nasal epithelia of patients with cystic fibrosis. Cell 1993;75:207-16.

\section{Discussion}

Dr Thomas M. Egan (Chapel Hill, NC). Dr Barlow and his colleagues from Stanford have had excellent results with a challenging group of patients. Forty patients with $\mathrm{CF}$ were among 47 with suppurative end-stage lung disease who underwent either heart-lung or double-lung transplantation with an operative survival of $94 \%$ and impressive 1-year actuarial survival.

We have performed double-lung transplantation in 79 patients with $\mathrm{CF}$ and have achieved a 1-year actuarial survival of $82 \%$ and a 5 -year actuarial survival of $58 \%$. Unlike your group, we have not excluded patients with Aspergillus or $B$ cepacia colonization. Given your excellent results, do you intend to liberalize your criteria to offer transplantation to more patients with $\mathrm{CF}$ ?

We have attempted to avoid $\mathrm{CPB}$, using it in fewer than $15 \%$ of our cases. Your data suggest that in the era of aprotinin, the use of CPB may be quite safe and acceptable for this operation.

I think the major issue here, though, is the appropriate dis- tribution of scarce donor organs for a variety of patients with end-stage thoracic diseases. In 1996, 805 lung transplantations were done, compared with only 39 heart-lung transplantations in the United States. Whereas deaths on both the lung and heart-lung lists continue to grow, there were more deaths on the list than transplantations for intended heart-lung recipients. In short, patients who need heart-lung transplantation are at a substantial disadvantage across the United States and are more likely to die waiting than to receive organs.

The authors allude in their manuscript to a peculiar local situation that has afforded them a relatively short waiting time for heart-lung recipients. I believe this is one of the accidents of geography that the new proposed rule for organ distribution by the Department of Health and Human Services is intended to address.

Subjecting patients with normal hearts to the risk of graft coronary disease is difficult to justify. What happens to the domino heart? Is it put back into the organ distribution algorithm for all potential recipients, or is this domino operation a veiled attempt at what some might consider cardiac piracy to enable a center to perform 2 transplantations when that center might only acquire 1 organ if another distribution algorithm were used?

This paper is an important contribution precisely because it demonstrates convincingly that there is no advantage of heart-lung transplantation over double-lung transplantation for patients with suppurative lung disease, and it will lend support to efforts to distribute allografts to potential heartlung recipients more equitably across the country.

Dr Barlow. The first of your 3 major questions concerns liberalization of criteria for transplantation. Of interest, the patient with graft failure who was relisted for heart-lung transplantation had a $B$ cepacia infection and pneumonia, and I think that may have put a temporary brake on liberalizing the listing of patients. The other issue, of course, is that we have several patients on our double-lung list at all times, and we are not looking for patients at the moment, we are looking for organs, so I think we are unlikely to liberalize criteria.

With regard to performing the procedure without CPB, I know from your own series that the bleeding times are prolonged as a consequence of the use of CPB. We have not done any operations without $\mathrm{CPB}$ at Stanford during the period that I have been there, but I am told by Dr Robbins and the other surgeons with more experience with it that it is considerably more difficult. Bleeding has not been a problem.

With regard to organ distribution, at Stanford the dominodonor heart goes into the pool, and often we will have a team from a different institution come and get the heart, so it does not become our own. This is not the case, for interest's sake, in the United Kingdom.

I think in terms of assessing which patients should have organs, the question can be answered in terms of both the individual patient and the transplantation population. We have 2 patients who are listed for a simultaneous liver transplantation, and they are both listed for heart-lung transplantation alone because of the shorter procedure times so they can move on to the second phase. 
With regard to others, patients at the extremes of heights and weights we would probably list for both procedures, and also very sick patients we would probably list this way so they can enjoy the benefits of both lists. Presumably that is a regional thing in California that does not apply elsewhere, but it does apply to us.

As far as the patient group is concerned, if you are in a center where distribution would give you the hearts, then the domino-donor heart from a non-brain dead donor with a preconditioned right ventricle would be nice to keep in your pool. It is also good to think that some other patient in our area is benefiting from that if it does not make any difference to the recipient with $\mathrm{CF}$ whether he or she receives a heartlung or a double-lung block, ultimately. As concerns the reports heard at this meeting, however, in which longer organ ischemic times may be associated in older donors with poorer survival and outcome, our average ischemic time for insertion of the second lung is $5 \frac{1}{2}$ hours. I believe other series have times closer to 7 hours, which was the cutoff reported at this meeting at which survival actually deteriorated. If you have a fair number of patients on your overall lists listed for heartlung transplantation, then you could accept organs from farther away, knowing that the insertion time is going to be shorter.

Dr G. Alexander Patterson (St Louis, Mo). With respect to the comment you just made, it seems to me that if the organs are coming from a really long way, the lung is more likely to function than the heart after transplantation. If you are talking about really long distances, you are limited more by cardiac ischemia than by lung ischemia.

You mentioned that allocation of recipients to heart-lung or lung transplantation is made on the basis of individual criteria, and I still do not understand that clearly. You mentioned the combined liver transplantation situation as one example. Is it also possible that you allocate patients to bilateral sequential lung transplantation or heart-lung transplantation depending on the availability of the organ? In other words, if you were offered a heart-lung block, would you just do a heart-lung transplantation by preference or would you do a bilateral lung transplantation by preference?

Dr Barlow. Until recently we had been listing patients for double-lung transplantation only. Our current philosophy is to return in effect to what the situation was about 5 years ago; that is, some patients are listed for both procedures if they get insurance clearance. Then we would be able to allocate a heart-lung block, if that was offered to us, whereas if we were only offered lungs and the heart was to go to a status I cardiac recipient, then we would do the double-lung transplantation. In terms of the individual patient criteria, the cases in which you might consider listing a patient for both procedures would be those in which you wanted that patient to enjoy the benefits of being on the two lists. 